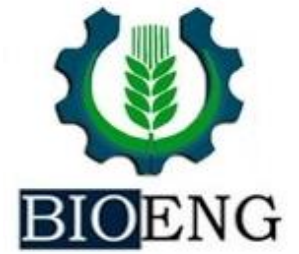

\section{DIAGNÓSTICO DA DEGRADAÇ̃̃O AMBIENTAL DE UMA ÁREA ÀS MARGENS DA CE- 292 EM CRATO-CE}

\author{
C. E. Bezerra*1; J. P. da Silva²; R. de S. Ferreira²; C. L. da Silva. A³;
} K. A. Rodrigues ${ }^{3}$; R. A. da Silva²; S. J.G. Rodrigues ${ }^{2}$

${ }^{1}$ Instituto Federal de Educação, Ciência e Tecnologia, Campus de Juazeiro do Norte, CE, Brasil.

${ }^{2}$ Faculdade de Tecnologia Centec - Fatec Cariri, CE, Brasil.

${ }^{3}$ Universidade Regional do Cariri- URCA, CE, Brasil.

Article history: Received 02 February 2020; Received in revised form 15 February 2020; Accepted 10 March 2020; Available online 31 March 2020.

\title{
RESUMO
}

Toda ação antrópica sobre o meio ambiente resulta em um impacto ambiental, seja negativo ou positivo. No caso da construção de uma rodovia, onde se retira parte da vegetação e se insere tantas interferências (como a poluição sonora) ao meio ecológico ali existente faz-se necessária a avaliação dos resultados da degradação causada pela ação humana. Portanto, este estudo objetivou avaliar e apresentar um diagnóstico de degradação ambiental de uma área às margens da CE-292 em Crato - CE, pela interferência antrópica. Para então, a partir dos conhecimentos dos impactos, fica viável adotar medidas de recuperação ou mitigação na área. Inicialmente procurou-se visitar o entorno da rodovia em questão para identificação dos efeitos e posterior categorização, através da metodologia "check-list". De acordo com os resultados, observou-se que os principais impactos ambientais diagnosticados foram o desmatamento, redução da flora nativa nas margens, deslocamento da fauna e intensificação dos processos erosivos e presença de resíduos sólidos.

Palavras-chave: Impactos ambientais. Construção de estrada. Desmatamento.

\section{DIAGNOSIS OF THE ENVIRONMENTAL DEGRADATION OF AN AREA AT THE MARGINS OF CE-292 IN CRATO-CE}

\begin{abstract}
Every human action on the environment results in an environmental impact, whether negative or positive. In the case of the construction of a highway, where part of the vegetation is removed and so many interferences (such as noise pollution) are inserted into the ecological environment there, it is necessary to evaluate the results of the degradation caused by human action. Therefore, this study aimed to evaluate and present a diagnosis of environmental degradation of an area on the margins of the CE-292 in Crato - CE, due to anthropic interference. Then, from the knowledge of the impacts, it is feasible to adopt recovery or mitigation measures in the area. Initially, an attempt was made to visit the surroundings of the highway in question to identify the effects and further categorization, through the "check-list" methodology. According to the results, it was observed that the main environmental impacts
\end{abstract}

*camila.esmeraldo23@gmail.com 
diagnosed were deforestation, reduction of native flora on the banks, displacement of fauna and intensification of erosive processes and the presence of solid waste.

Keywords: Environmental impacts. Road construction. Deforestation.

\section{INTRODUÇÃO}

O transporte terrestre é um dos elementos essenciais da atividade econômica, pois após a produção dos produtos eles são distribuídos em todo o país ou outros países. Entretanto, para que haja o transporte de produtos ou deslocamento de pessoas, para outras cidades, é preciso a existência de estradas.

A construção de estradas é crucial, para melhorar a qualidade de vida das pessoas, além de contribuir com aspectos tanto sociais, quanto econômicos. Desde tempos remotos, que a construção de estradas é alvo de interesse, tendo em vista a facilidade de acesso entre as cidades circunvizinhas, gerando melhorias no setor econômico, já que favorece ao transporte de mercadorias aumentando a geração de renda e novos empregos (MAGALHÃES; MARTINS; SANTOS, 2011).

Toda atividade ou obras de construção civil, que modifica o espaço natural, geram impactos positivos $\mathrm{e}$ negativos, a presença de estradas não é diferente, causa degradação no meio ambiente.

Dependendo do impacto causado pelas atividades antrópicas, o ecossistema pode sofrer tanto com a perturbação, que perde a capacidade de se recuperar e tornar ao estado anterior a perturbação. Dessa forma tem- se uma área degradada. Quando fauna, flora, solo e corpos hídricos sofrem modificações de suas propriedades física, químicas e biológicas, pode- se afirmar que houve uma degradação ambiental (ROTH; GARCIAS, 2009).

O uso do solo está relacionado diretamente com a degradação do meio ambiente pelas ações antrópicas podendo ser diretas ou indiretas. Estas ações podem variar em grau de intensidades, conforme a função que um determinado ambiente assume, decorrente da apropriação dos seus recursos naturais, normalmente priorizando-se o fator socioeconômico gerando consequências no meio natural (CHUEH; SANTOS, 2005).

Os impactos ambientais decorrentes da ação do homem estão se agravando cada vez mais, podendo citar como exemplo, as consequências sobre um solo degradado, a erosão e o depósito de resíduos no mesmo, acarretando na contaminação superficial do lençol freático. Vale ressaltar que um ambiente que sofreu algum impacto da ação do homem, está em desequilíbrio, então a fauna e flora daquele lugar podem sofrer efeitos negativos.

São os interesses econômicos e sociais que se sobrepõem sobre as questões ambientais, em se tratando do desenvolvimento e do lucro que determinados empreendimentos trazem para algum local. Já a preservação e o equilíbrio do ambiente não são vistos como prioridades. Há leis ambientais, mas que se limitam muitas vezes somente ao papel, necessitando de fiscalizações a fim de verificar as condições do equilíbrio sócioambientais.

Diante do exposto, faz- se necessário preservar os ecossistemas, essenciais para a manutenção da vida. Ainda há muitos desafios, seja na teoria ou na prática, na conscientização das pessoas ou até mesmo no envolvimento da sociedade como um todo, nas questões ambientais.

Outro ponto importante é a realização de monitoramentos dos impactos tanto na fase de construção das estradas, quanto de operação.

Visto isso o pressuposto que norteia este trabalho é avaliar e apresentar um diagnóstico de degradação ambiental 
de uma área às margens da CE-292 em Crato - CE, pela interferência antrópica. Conhecendo esses impactos, é possível

\section{MATERIAIS E MÉTODOS}

\section{Área de estudo}

O estudo foi empreendido na rodovia CE-292, no trecho situado no bairro Batateiras, município de Crato/CE (Figura 01). O município de Crato localiza-se no sul do estado do Ceará, na região do Cariri, conforme a figura a seguir. Possui uma população estimada em 131.372 habitantes (IBGE, 2019). Encontra-se sob as coordenadas geográficas de latitude $7^{\circ} 14^{\prime} \quad 03^{\prime \prime}$ e adotar medidas de recuperação ou mitigação na área. longitude $39^{\circ} 24^{\prime} 34^{\prime \prime}$, distante $508 \mathrm{~km}$ da capital do estado (IBGE/IPECE, 2019). O clima é tropical quente semiárido, brando e tropical quente sub-úmido, com pluviosidade média em torno de 1090,9 $\mathrm{mm}$ e relevo caracterizado pela Chapada do Araripe e Depressões Sertanejas (FUNCEME, 2019). Os dados para o levantamento das variáveis causadoras da degradação ambiental foram realizados através do método de check-list.

Figura 01: Vista da CE-292 Crato - CE pelo Google Maps.

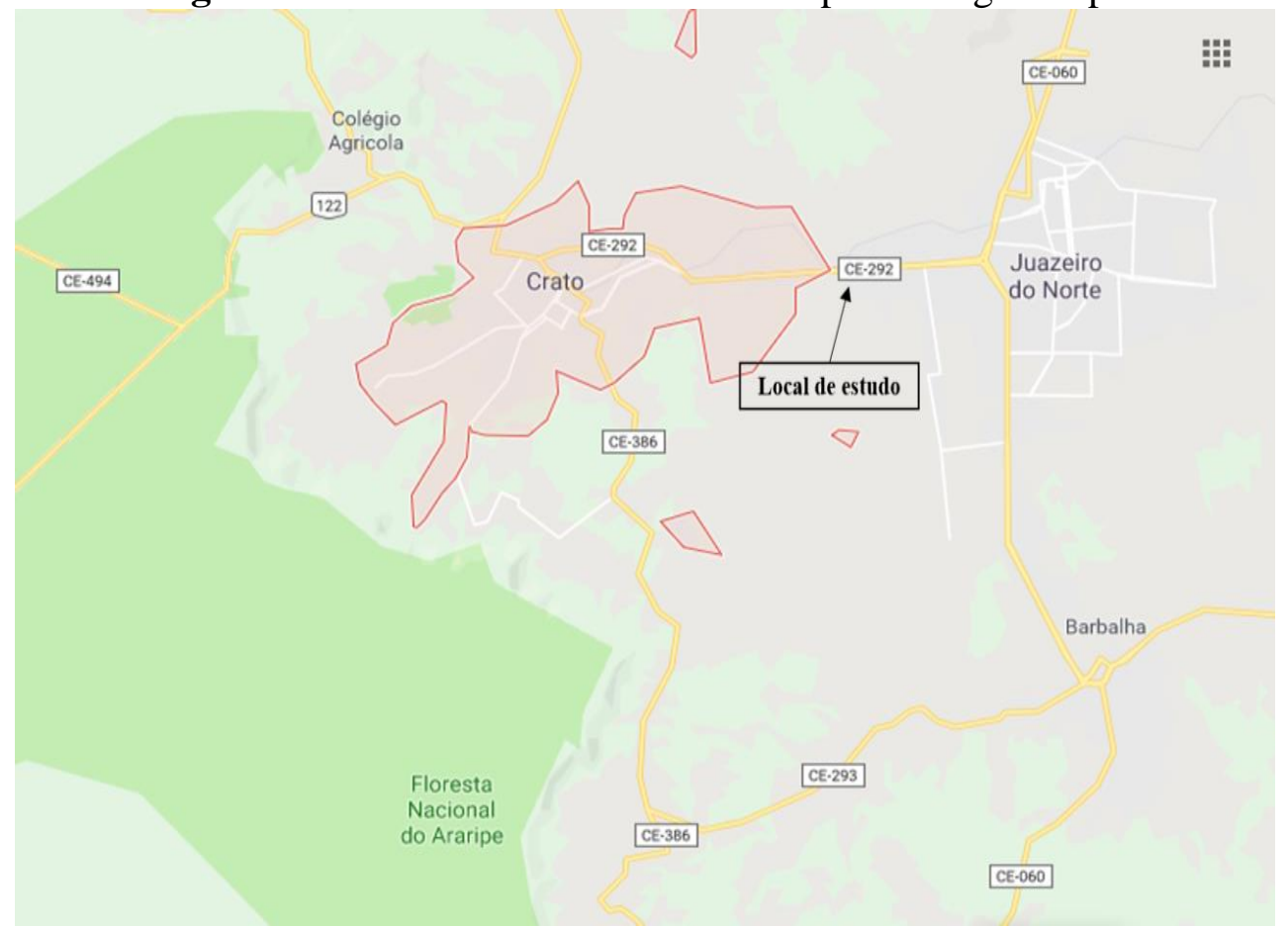

Fonte: Google Maps. Adaptado pelos autores.

A CE-292 foi recentemente restaurada por intermédio do governo do estado, com vista à melhoria do fluxo rodoviário e segurança viária nos trechos em que a rodovia está presente, proporcionando mais conforto para os usuários. $\mathrm{O}$ processo de restauração causou, indubitavelmente, impactos ambientais visíveis de diferentes intensidades ao longo da extensão da rodovia. Sabendo-se disso, procurou-se conhecer e avaliar de perto tais impactos, e como estes afetam direta e indiretamente a fauna e a flora da Floresta Nacional do Araripe - FLONA e a vida dos moradores das adjacências.

\section{Diagnóstico prévio}

Através da ferramenta de sensoriamento Google Earth pode-se 
localizar a área de estudo e ter uma visualização prévia, para a observação da extensão e de proximidades, permitindo dados relativos ao diagnóstico e para melhor planejamento da visita em campo e definição da área (Figura 02):

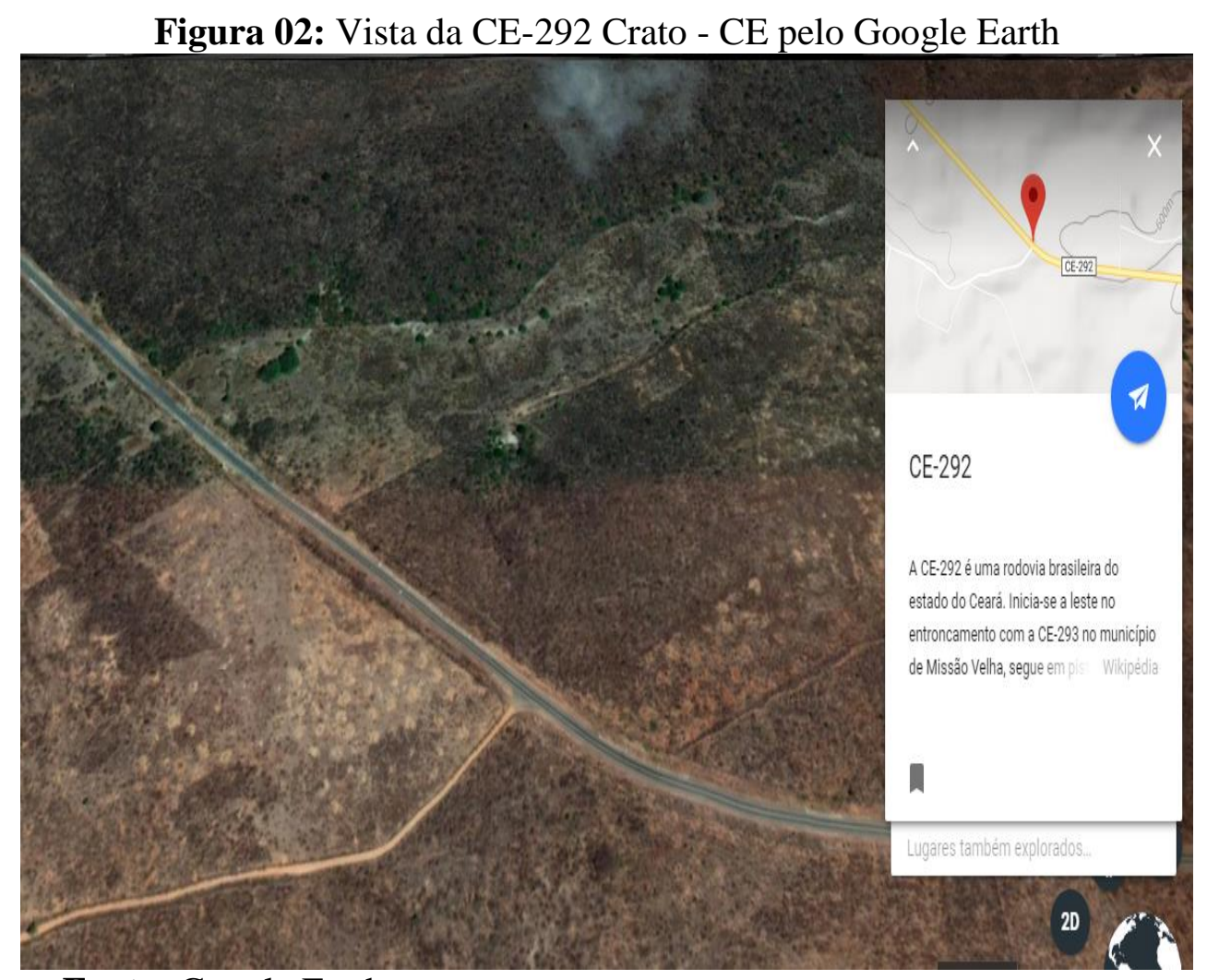

Fonte: Google Earth

A descrição da área de estudo foi realizada a partir de pesquisas bibliográficas em livros, trabalhos acadêmicos e técnicos realizados na área, visitas de campo e com uso de registros fotográficos, as quais permitiram dados relativos ao diagnóstico da degradação ambiental na área degradada.

\section{Diagnóstico em campo}

Foi realizada uma visita na área às margens da CE-292 em Crato - CE, no mês Caracterização e análise dos impactos de dezembro de 2018, para se observar o real estado da área em questão e identificar as ações degradantes existentes no local. Durante a visita foram observados elementos como: área de vizinhança, as características, distribuição e acomodação dos resíduos sólidos e a condição ambiental atual dos fatores ambientais para os meios: abiótico, biótico e antrópico. Realizaram-se também registros fotográficos do local. 
Tabela 01 - Critérios qualitativos para análise dos impactos.

\begin{tabular}{|c|c|c|}
\hline CRITÉRIOS & PARÂMETROS & SIGNIFICADO \\
\hline \multirow{2}{*}{ Ordem } & \multirow{2}{*}{$\begin{array}{l}\text { Direto } \\
\text { Indireto }\end{array}$} & Quando o impacto é considerado primário. \\
\hline & & $\begin{array}{l}\text { Quando o impacto é uma reação secundária da ação } \\
\text { que está sendo realizada. }\end{array}$ \\
\hline \multirow[t]{2}{*}{ Plástica } & \multirow{2}{*}{$\begin{array}{l}\text { Reversível } \\
\text { Irreversível }\end{array}$} & $\begin{array}{l}\text { Quando o fator ambiental impactado, pode ser } \\
\text { recuperado. }\end{array}$ \\
\hline & & $\begin{array}{l}\text { Quando o fator ambiental, não é passível de } \\
\text { recuperação. }\end{array}$ \\
\hline \multirow{2}{*}{ Valor } & \multirow{2}{*}{$\begin{array}{l}\text { Positivo } \\
\text { Negativo }\end{array}$} & $\begin{array}{l}\text { Quando a ação é benéfica para a melhoria da } \\
\text { qualidade ambiental. }\end{array}$ \\
\hline & & $\begin{array}{l}\text { Quando a ação resulta em dano à qualidade de um } \\
\text { fator ambiental. }\end{array}$ \\
\hline \multirow{3}{*}{ Dinâmica } & \multirow{3}{*}{$\begin{array}{c}\text { Temporário } \\
\text { Permanente } \\
\text { Cíclico Imediato }\end{array}$} & $\begin{array}{l}\text { Quando permanece por um determinado tempo, após a } \\
\text { realização da ação. }\end{array}$ \\
\hline & & $\begin{array}{l}\text { Quando a ação é executada e os efeitos não cessam de } \\
\text { se manifestar em um determinado horizonte } \\
\text { conhecido. }\end{array}$ \\
\hline & & O efeito se faz sentir em determinados períodos. \\
\hline \multirow{3}{*}{ Tempo } & \multirow{3}{*}{$\begin{array}{l}\text { Curto Prazo } \\
\text { Médio Prazo } \\
\text { Longo Prazo }\end{array}$} & $\begin{array}{l}\text { Surge no momento em que a ação está sendo } \\
\text { realizada. } \\
\text { Curto Prazo Surge em curto prazo. }\end{array}$ \\
\hline & & $\begin{array}{l}\text { Quando o efeito se manifesta após certo tempo que a } \\
\text { ação foi } \\
\text { Realizada. }\end{array}$ \\
\hline & & $\begin{array}{l}\text { Quando o efeito se manifesta um longo tempo depois } \\
\text { de decorrido um certo tempo após a ação. }\end{array}$ \\
\hline \multirow{3}{*}{ Espaço } & \multirow{3}{*}{$\begin{array}{l}\text { Regional } \\
\text { Nacional }\end{array}$} & $\begin{array}{l}\text { Quando a ação afeta apenas o próprio local e suas } \\
\text { imediações. }\end{array}$ \\
\hline & & $\begin{array}{l}\text { Quando o efeito se propaga além do local e de suas } \\
\text { imediações. }\end{array}$ \\
\hline & & Quando o efeito se propaga em um grande espaço \\
\hline
\end{tabular}

Fonte: SANCHEZ, 2008 


\section{RESULTADOS E DISCUSSÃO}

Todos os impactos foram negativos, mas o meio biótico é o que está mais vulnerável a degradações, já que a maioria dos impactos são diretos, porém reversíveis (Tabela 01). $\mathrm{O}$ aspecto que tem mais impactos diretos são fauna, flora, água e solo.

Uma área degradada é aquela em que a ação antrópica causou tanta perturbação, que ela não consegue se restabelecer a condição anterior. Entretanto, para os impactos, os quais são reversíveis mesmo que não retornem às características ao estado anterior a atividade antrópica, medidas de mitigação corretiva podem ser tomadas. Dessa forma, torna o ecossistema um ambiente em que os seres vivos presentes possam encontrar um equilíbrio, para sua sobrevivência.

Magalhães; Martins e Santos (2011), consideram a recuperação de uma área em torno de uma estrada essencial, pelo fato da área que sofreu o impacto poder se regenerar de forma natural conforme tenha sido o processo de degradação e dessa forma elaborar medidas que possam atenuar os prejuízos ocasionados pela construção da área adjacente, promovendo o desenvolvimento sustentável do ecossistema afetado.

Constatou-se as seguintes atividades de degradação do local (Tabela 02): desmatamento, supressão da vegetação nativa, presença de resíduos sólidos e alteração dos habitats. Por meio da metodologia check-list, identificou- se os impactos existentes, devido à atividade degradante no local de estudo, são eles: erosão, proliferação de vetores por água contaminada e resíduos sólidos no local, existência de espécies exóticas de planta, desvalorização imobiliária e perda da biodiversidade. 
Tabela 02- Protocolo de Avaliação da Degradação Ambiental em uma área Terrestre.

\begin{tabular}{|c|c|c|c|c|c|c|}
\hline \multirow{3}{*}{\begin{tabular}{|l} 
IMPACTOS \\
\\
Desmatamento.
\end{tabular}} & \multicolumn{2}{|c|}{ MEIO BIÓTICO } & \multicolumn{2}{|c|}{ MEIO ABIÓTICO } & \multicolumn{2}{|c|}{$\begin{array}{l}\text { MEIO } \\
\text { SOCIOECONÔMICO }\end{array}$} \\
\hline & Fauna & Flora & Água & Solo & $\begin{array}{l}\text { Saúde } \\
\text { Pública }\end{array}$ & $\begin{array}{l}\text { Conflitos } \\
\text { Ambientais }\end{array}$ \\
\hline & $\begin{array}{l}\text { N, D, IR, } \\
\text { IM, LP, } \\
\text { LO }\end{array}$ & $\begin{array}{l}\text { N, D, IR, } \\
\text { IM, LP, } \\
\text { LO }\end{array}$ & $\begin{array}{l}\text { N, D, R, } \\
\text { CP, PR, } \\
\text { LO }\end{array}$ & $\begin{array}{l}\text { N, D, R, } \\
\text { CP, PR, } \\
\text { LO }\end{array}$ & $\begin{array}{l}\mathbf{N}, \quad \mathbf{I}, \quad \mathbf{R}, \\
\mathbf{M P}, \mathbf{C}, \mathbf{L O}\end{array}$ & $\begin{array}{l}\text { N, I, IR, CP, } \\
\text { PR, LO }\end{array}$ \\
\hline $\begin{array}{l}\text { Perda da } \\
\text { Biodiversidade } \\
\text { local Fauna/Flora. }\end{array}$ & $\begin{array}{l}\text { N, I } \\
\text { IR, IM, } \\
\text { PR, LO }\end{array}$ & $\begin{array}{l}\text { N, D, IR, } \\
\text { IM, CP, } \\
\text { LO }\end{array}$ & $\begin{array}{l}\text { N, D, R, } \\
\text { IR, PR, } \\
\text { LO }\end{array}$ & $\begin{array}{l}\text { N, D, R, } \\
\text { CP, PR, } \\
\text { LO }\end{array}$ & $\begin{array}{l}\text { N, I, IR, } \\
\text { MP, } \\
\text { LO }\end{array}$ & $\begin{array}{l}\text { N, D, IR, MP, } \\
\text { PR, LO }\end{array}$ \\
\hline Erosão & $\begin{array}{l}\text { N, D, R, } \\
\text { MP, PR, } \\
\text { LO }\end{array}$ & $\begin{array}{l}\text { N, D, IR, } \\
\text { MP, PR, } \\
\text { LO }\end{array}$ & $\begin{array}{l}\text { N, D, R, } \\
\text { PR, LO }\end{array}$ & $\begin{array}{l}\text { N, D, R, } \\
\text { CP, PR, } \\
\text { LO }\end{array}$ & $\begin{array}{l}\text { N, I, } \\
\text { MP, } \\
\text { LO }\end{array}$ & $\begin{array}{l}\text { N, I, R, MP, } \\
\text { PR, C }\end{array}$ \\
\hline $\begin{array}{l}\text { Proliferação de } \\
\text { Vetores por Água } \\
\text { contaminada }\end{array}$ & $\begin{array}{l}\text { N, I, R, } \\
\text { MP, PR, } \\
\text { LO }\end{array}$ & $\begin{array}{l}\text { N, I, R, } \\
\text { CP, PR, } \\
\text { LO }\end{array}$ & $\begin{array}{l}\text { N, I, R, } \\
\text { CP, PR, } \\
\text { LO }\end{array}$ & $\begin{array}{l}\text { N, I, R, } \\
\text { CP, PR, } \\
\text { LO }\end{array}$ & $\begin{array}{l}\text { N, I, } \mathbf{R}, \\
\text { CP, } \\
\text { LO }\end{array}$ & $\begin{array}{l}\text { N, I, R, CP, PR, } \\
\text { LO }\end{array}$ \\
\hline $\begin{array}{l}\text { Desvalorização } \\
\text { Imobiliária }\end{array}$ & $\begin{array}{l}\mathbf{N}, \mathbf{I}, \mathbf{R}, \\
\mathbf{C P}, \quad \mathrm{T}, \\
\mathbf{L O}\end{array}$ & 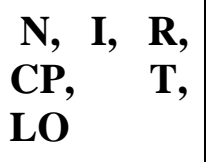 & $\begin{array}{l}\text { N, I, R, } \\
\text { CP, T, } \\
\text { LO }\end{array}$ & 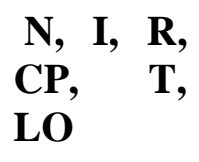 & $\begin{array}{l}\mathbf{N}, \quad \mathbf{I}, \mathbf{R}, \\
\mathbf{C P}, \mathbf{T}, \mathbf{L O}\end{array}$ & $\begin{array}{l}\text { N, I, R, CP, T, } \\
\mathbf{L O}\end{array}$ \\
\hline
\end{tabular}

Fonte: Dados da Pesquisa

Legenda: D: Direta; I: Indireta; N: Negativa; P: Positivo; T: Temporário; PE: Permanente; IM: Imediato; CP: Curto Prazo; MP: Médio Prazo; LP: Longo Prazo; LO: Local; RG: Regional; IR: Irreversível; R: Reversível.

Foi identificado a presença de resíduos sólidos (figura 03), materiais diversificados como embalagens de produto de higiene e limpeza, sacolas plásticas e metal.

A geração de resíduos sólidos, que são jogados na beira das estradas, acarretam em impactos ambientais tais como: poluição visual das populações flutuantes e locais, além de atingir também a fauna do local e contaminação do solo e dos recursos hídricos, assoreamento, enchentes e aumento de vetores transmissores de doenças ( MORETTI; MORETTI; SILVA, 2013).

Barbosa e Correia (2015), adverte sobre a disposição inadequada de qualquer resíduo no solo, pois existem alguns fatores que modificam as suas características como o tempo de exposição, causando altas concentrações de substância que não parecem ser tóxicas, entretanto acarretam em prejuízos na qualidade ambiental do local e na saúde das pessoas que moram próximas. O correto é não haver a disposição incorretas dos resíduos, pois evita a contaminação do solo e da água.

Esse descarte inadequado dos resíduos sólidos, evidencia a necessidade de conscientizar a população próxima ao trecho analisado, como também a população ondulante a fim de evitar a poluição visual, contaminação do solo e prejuízos a fauna local. Através de uma educação ambiental, as pessoas têm acesso aos conhecimentos das consequências negativas que o lixo traz.

A educação ambiental no Brasil tem procurado se basear em uma visão 
interdisciplinar, a fim de entender as dúvidas, que atingem os grupos humanos e seu ambiente e intervir nelas, fazendo uso dos conhecimentos em áreas e diversos saberes. Não apenas no ambiente escolar como comunidades e populações locais, dessa forma valorizando as diferenças culturais e os modos de entendimento e manejo do ambiente (CARVALHO, 2017).

Figura: 03: Presença de resíduos sólidos.

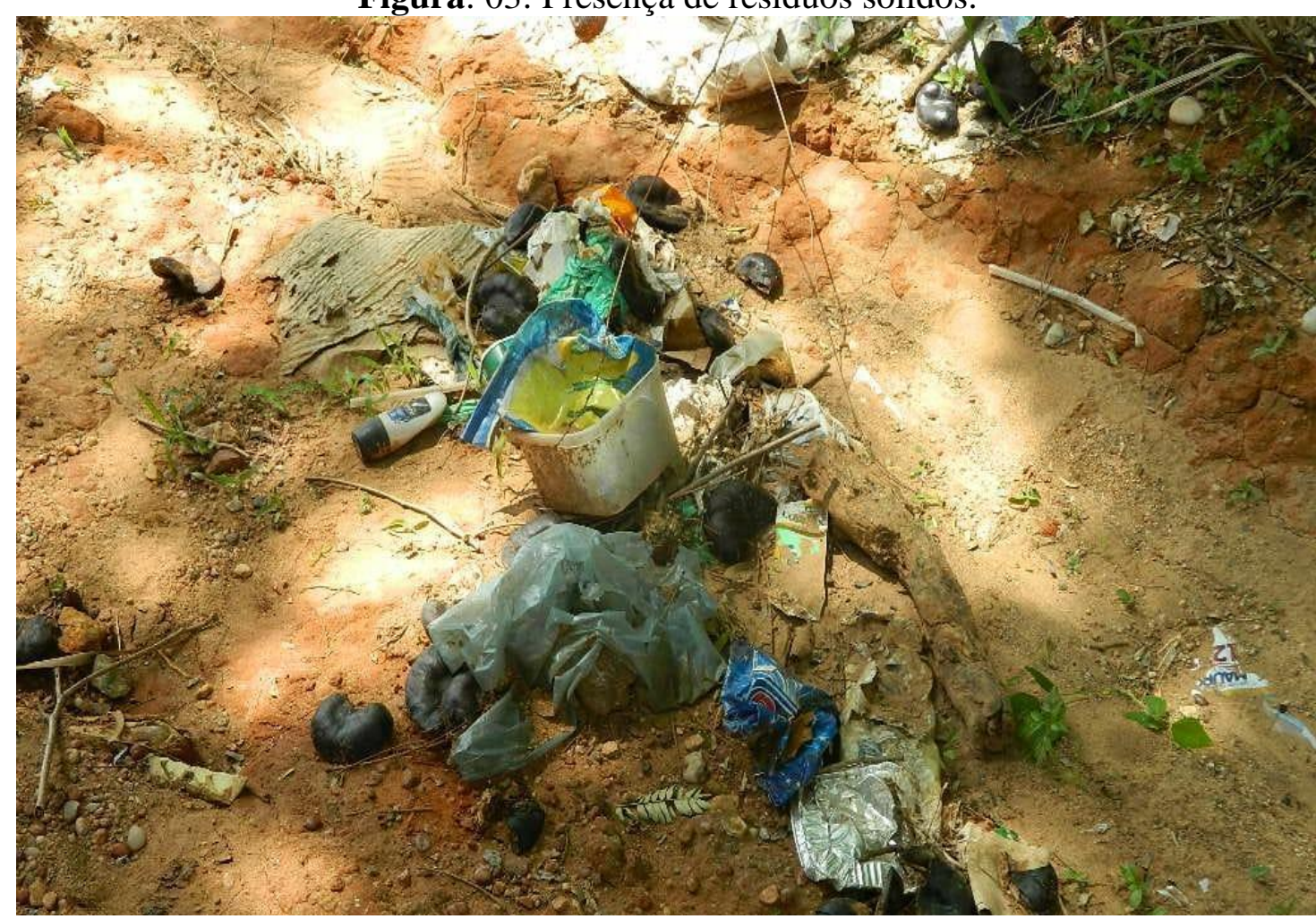

Fonte: Autoria própria dos autores, 2019.

O solo já se encontra em um estágio avançado de erosão (Figura 04), mas ainda pode ser recuperado com algumas técnicas e implementação em longo período. Como se percebe o solo está com pouca ou nenhuma vegetação necessitando de cobertura do mesmo. Segundo Costa (2007), a erosão pode ser causada pelo o homem através de uma drenagem deficiente, que concentra grande volume de água do escoamento, como existe em objetos ao longo das estradas.

São vários os fatores que causam a erosão do solo em estradas. Castro; Ferreira e Santos (2006), afirmam que um dos que se destacam é a erosão, a qual já surge desde o início da obra de construção da estrada. Salientam ainda as principais causas: desmatamento desordenado da área que compreende a estrada da rodovia; displicência com rotas de trabalho utilizadas sem terem sido recuperadas; má distribuição do bota-fora; dimensionamento deficiente das obras, entre outras causas. Como se percebe, a construção de rodovias deve ser monitorada em todas as suas fases, pois acarretam em impactos ambientais de várias magnitudes tanto na fase de implantação, quanto de operação. 
Figura: 04: Erosão acelerada

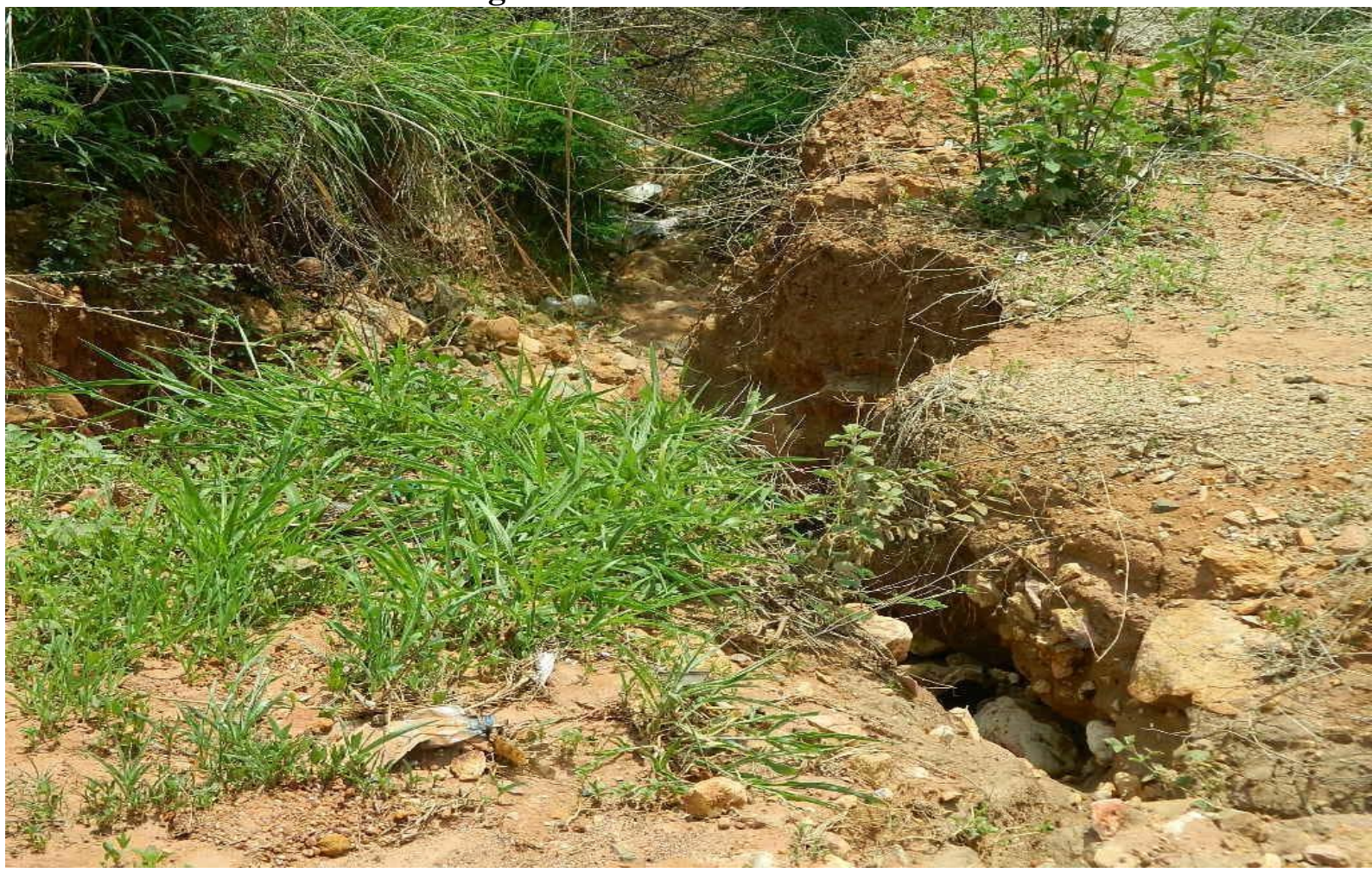

Fonte: Autoria própria dos autores, 2019.

Outro aspecto observado no local (Figura 5), em consequência da supressão da vegetação além da erosão, foi o acúmulo de água trazendo como consequência a proliferação de vetores transmissores de doenças, para as pessoas que residem na região adjacente ou pessoas que visitam o local e ainda contaminação do solo.

A vegetação, é a proteção do solo e mantém o equilíbrio natural dele. A retirada da cobertura vegetal deixa o solo suscetível à ação de agentes naturais como o sol, chuva e ventos, tornando- o frágil. Dessa forma o processo de degradação ocorre, tendo a chuva como elemento principal, acarretando na erosão (Dyonísio, 2010).

A vegetação filtra a água da chuva, minimizando o impacto das gotas da chuva no solo, consequentemente a falta dela, dificulta a drenagem dele, que além da erosão pode acarretar no acúmulo da água. Dessa forma, na obra de construção de estradas deve ser realizado o projeto de drenagem.
$\mathrm{O}$ projeto de drenagem de rodovias, tem por objetivo desenvolver métodos, que viabilizem a proteção no que diz respeito tanto a estrada, quanto ao meio ambiente. É nesse projeto, que estão presentes os mecanismos de drenagem, cuja finalidade é captar e conduzir a água para um local apropriado (RODRIGUES; SUZUKI; TAVARES, 2016).

Existe outra problemática envolvendo a falta de drenagem, é o acúmulo de água, que pode trazer riscos a saúde da população local e flutuante, já que essa situação gera a proliferação de vetores que transmitem doenças. Um dos principais vetores que se reproduzem em água parada, limpa ou pouca poluída é o Aedes aegypt.

Houve um aumento da presença do Aedes aegypt no Brasil, transmissor da dengue e febre amarela. A Dengue, Zika e Chicungunha, são doenças transmitidas principalmente pelo Aedes aegypt. O que torna a situação mais agravante é o fato de ainda não haver vacinas, para essas doenças. Como a população está frequentemente exposta ao vetor, torna- se 
mais vulnerável de ser contagiada (MARTINS; SALDANHA; SNT' ANA, 2016). Diante de todos esses riscos à saúde da população, a melhor forma é a prevenção, evitando o acúmulo de água parada.

Figura 05: Acúmulo de água

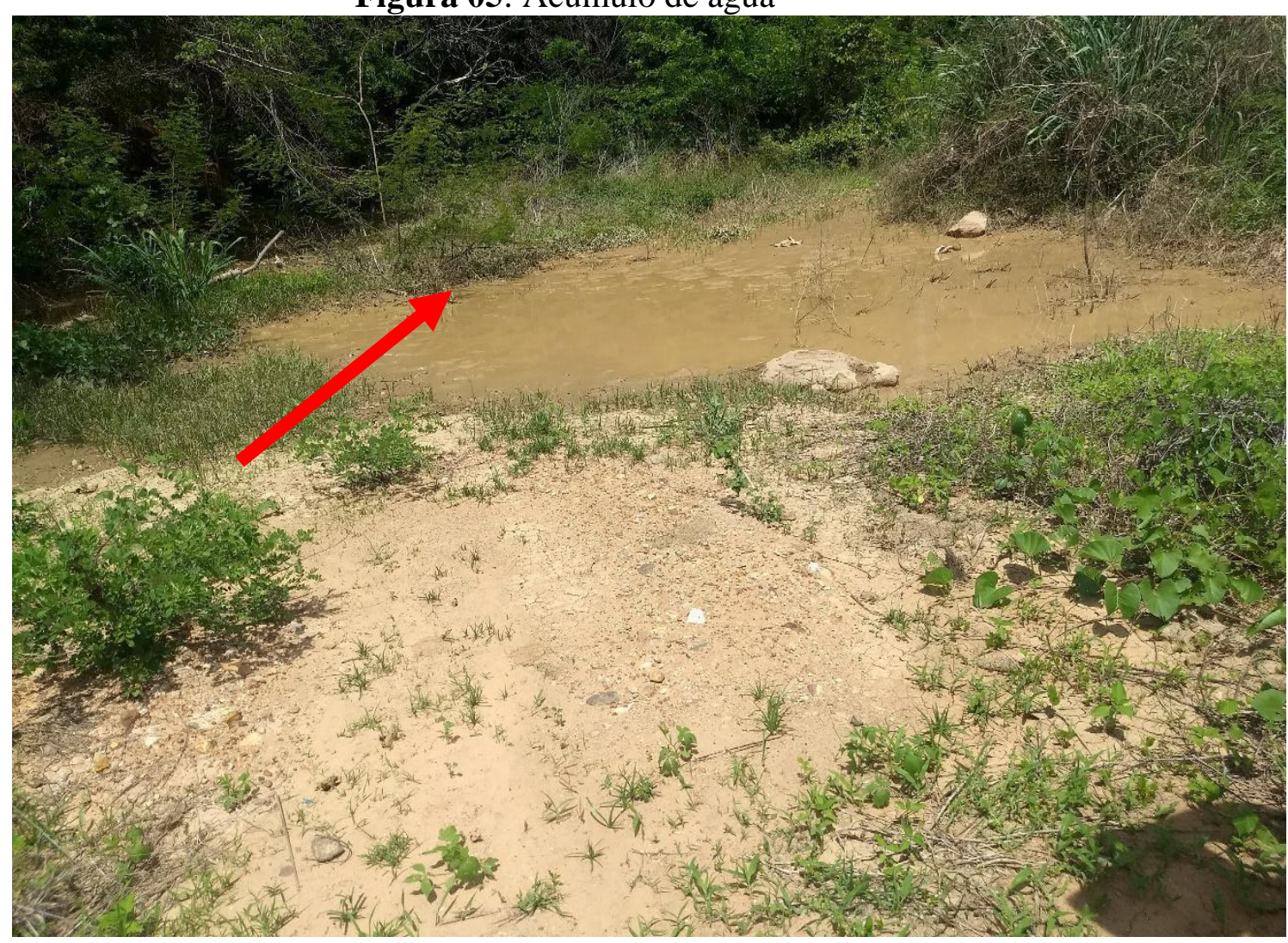

Fonte: Autoria própria dos autores, 2019.

\section{CONCLUSÃO}

A degradação do meio ambiente pode ser resultado de inúmeras interferências em diferentes intensidades sem que haja, portanto, sensibilidade por parte do agente causador sobre sua forma de uso dos recursos naturais, como do solo, por exemplo. Sua ocupação irregular ou inadequada acarreta grande desequilíbrio ambiental, visto que sua utilização coloca em risco os processos ecológicos que ocorrem em determinada extensão.

Supressão da camada vegetal, alteração na dinâmica do ciclo hidrológico, ação poluidora pela interferência humana e aumentos nos processos erosivos são aspectos decorrentes do uso e ocupação do espaço que ampliaram significativamente a degradação ao redor da rodovia CE-292.
Desse modo, de acordo com os dados deste estudo as seções que constatam mais impactos diretos foram: fauna, flora e solo. Sobretudo, no que se relaciona ao desmatamento, perda da biodiversidade local e erosão nas proximidades da via.

No entanto, apesar dos itens identificados serem significantes, se faz necessária mais profunda análise das consequências causadas pela obra, para melhor possibilitar o entendimento dos níveis dos efeitos negativos e sua evolução, como também a elaboração de um sistema de minimização ou recuperação dos impactos na área afetada, buscando a conservação do bioma ali existente. 


\section{REFERÊNCIAS}

BARBOSA, A. A; CORRÊA, A. A. Caracterização química de solo contaminado por resíduos sólidos urbanos na estrada Arroio Pavuna em Jacarepaguá no município Rio de Janeiro. Revista ENGEVISTA, V. 17 , n. 2, p. 266-272, jun. 2015.

\section{CARVALHO, I. C.M. Educação}

Ambiental: a Formação do sujeito ecológico. São Paulo: Cortez, 2017.

CASTRO, R. A; FERREIRA, H. L;

SANTOS, L. C. dos. Erosões às margens da Br 222 na cidade de Açailândia - Ma. In: SIMPÓSIO NACIONAL DE GEOMORFOLOGIA, 6., 2006, Goiânia.

ANAIS [...]. Goiânia: União da

Geomorfologia Brasileira. 2006.

CHUEH, A. M.; SANTOS, L. J. C. Análise do Potencial de Degradação Ambiental na bacia. 2005. Acesso em 15 dez. 2018.

COSTA, F. L. Contribuições para o conhecimento dos processos erosivos em Cabo Verde. Disponível em: $<$ http://geoinova.fcsh.unl.pt/revistas/fil es/n9-12.pdf $>$. Acesso em: 19 de jan. 2018.

DYONÍSIO, H. A. F. Erosão hídrica: suscetibilidade do solo. Revista Eletrônica Thesis, São Paulo, ano VII, n. 13, p. 15-25, $1^{\circ}$ semestre, 2010.

FUNCEME. Fundação Cearense de Meteorologia e Recursos Hídricos. Calendário das Chuvas no Estado do Ceará. Disponível em: <http://www.funceme.br/app/calendario/pr oduto/municipios/maxima/diario?data=hoj e>. Acesso em: 23 de dez. 2018.

IBGE. Instituto Brasileiro de Geografia e Estatística. Dados demográficos e geográficos. Disponível em: <https://cidades.ibge.gov.br/brasil/ce/crato/ panorama>. Acesso em: 28 de dez. 2018. IPECE. Instituto de Pesquisa e Estratégia Econômica do Ceará. Perfil
Municipal 2017 Crato. Disponível em: <https://www.ipece.ce.gov.br/wpzontent/uploads/sites/45/2018/09/Crato_20 17.pdf>. Acesso em 23 de dez. 2018.

MAGALHÃES, I. A. L; MARTINS, R. F; SANTOS, A. R. dos. Identificação dos impactos ambientais relacionados à pavimentação da rodovia MG 307 no município de Grão Mogol - MG. Revista Verde de Agroecologia e Desenvolvimento Sustentável. Mossoró, v.6, n.5, p. 10 - 16, dez. 2011.

MARTINS, A. P; SALDANHA, L.S; SNT' ANA, D. S. IN: COLÓQUIO ESTADUAL DE PESQUISA MULTIDISCIPLINAR,1., 2016, Mineiros. Anais... Mineiros: Unifimes, 2016.

MORETTI, M. S; MORETTI, R. D. S; SILVA, E. M. Impactos ambientais da estrada mt-325, em Alta Floresta, Mato Grosso. Disponível em:< http://portal.unemat.br/media/files/IMPAC TOS\%20AMBIENTAIS\%20DA\%20EST RADA\%20MT325,\%20EM\%20ALTA\%2 OFLORESTA,\%20MATO\%20GROSSO.p df>. Acesso em: 02 mar. 2020.

RODRIGUES, C. G. S; SUZUKI, C. Y. O; TAVARES, M. B. Drenagem em rodovias: drenagem profunda ou subterrânea. Centro Universitário Toledo. São Paulo, 2016. Disponível em :<http://www.unitoledo.br/repositorio/handl e/7574/256>. Acesso em: 05 mar. 2020.

ROTH, C. G; GARCIAS, C. M.

Construção Civil e a Degradação Ambiental. Revista Desenvolvimento em Questão, V. 7, n. 13, p. 111- 128, jan./ jun. 2009.

SANCHÉZ, L. E. Avaliação de Impacto Ambiental: conceitos e métodos. São Paulo: Oficina de Textos, 2008. 